\title{
Enhancement of Natural Killer Function Through Activation of the T11 E Rosette Receptor
}

Reinhold E. Schmidt, Jean M. Michon, John Woronicz, Stuart F. Schlossman, Ellis L. Reinherz, * and Jerome Ritz Division of Tumor Immunology and *Laboratory of Immunobiology, Dana-Farber Cancer Institute, Department of Medicine, Harvard Medical School, Boston, Massachusetts 02115

\begin{abstract}
Natural killer (NK) cells, which represent a small fraction of normal peripheral blood mononuclear cells, were purified by immunofluorescent cell sorting of $\mathrm{NKH1}^{+}$cells. Cytotoxicity of $\mathrm{NKH1}^{+}$cells could be enhanced through activation by monoclonal antibodies (anti- $\mathrm{T11}_{2}$ and anti-T11 ${ }_{3}$ ) specific for epitopes of the sheep erythrocyte receptor or by recombinant interleukin-2 (rIL2). After $18 \mathrm{~h}$, incubation with both anti-T11 $1_{2 / 3}$ and $\mathrm{rIL}-2$ resulted in similar levels of enhanced cytotoxicity against NK-resistant as well as NK-sensitive targets. Before and after induction, cytotoxicity was found predominantly within the $\mathrm{NKH1}^{+}$population. These results suggest that several distinct mechanisms may be capable of enhancing NK activity and that the cells responsible for lymphokine-activated killing are likely to be the same population capable of spontaneous or natural killing before activation in vitro.
\end{abstract}

\section{Introduction}

Natural killer (NK) ${ }^{1}$ cells have been operationally defined as a population of lymphocytes capable of mediating direct cytotoxicity against a variety of target cells without prior immunization (1). Although NK cells in peripheral blood have been shown to be phenotypically and functionally heterogeneous (2), they appear morphologically as a relatively homogeneous population of large granular lymphocytes. Moreover, there are some NKassociated antigens that appear to be expressed on all NK cells and only rarely on other cell types. One of these antigens, termed $\mathrm{NKH} 1$, is a $200-\mathrm{Kd}$ structure that is only expressed on $10-12 \%$ of peripheral blood mononuclear cells (PBMC) (3). $\mathrm{NKH}^{+}$cells appear morphologically as LGL. All NK activity in peripheral

Address correspondence to Dr. Jerome Ritz, Division of Tumor Immunology, Dana-Farber Cancer Institute, 44 Binney Street, Boston, MA 02115.

Dr. Schmidt's present address: Abteilung Immunologie und Transfusionsmedizin, Zentrum Innere Medizin und Dermatologie, Medizinische Hochschule Hannover, Postfach 610180, D-3000 Hannover, FRG.

Received for publication 7 August 1986

1. Abbreviations used in this paper: $\mathrm{CD} 2, \mathrm{~T} 11 / \mathrm{E}$ rosette receptor; $\mathrm{E} / \mathrm{T}$, effector/target ratio; LAK, lymphokine-activated killing; NK, natural killer; PBL, peripheral blood lymphocytes; PBMC, peripheral blood mononuclear cells; rIL-2, recombinant interleukin-2.

J. Clin. Invest.

(c) The American Society for Clinical Investigation, Inc.

$0021-9738 / 87 / 01 / 0305 / 04 \$ 1.00$

Volume 79, January 1987, 305-308 blood is contained within the $\mathrm{NKH} 1^{+}$population. $\mathrm{NKH} 1$ is not expressed by $\mathrm{B}$ cells, monocytes, or granulocytes and is expressed only on a minor population of $\mathrm{T}$ cells. Of note, $\mathrm{NKH} 1^{+} \mathrm{T} 3^{+}$ cells in peripheral blood have also been shown to have broad cytolytic activity similar to that of $\mathrm{NKH}^{+}{ }^{+} \mathrm{T}^{-}$cells, which represent the majority of $\mathrm{NK}$ active cells (4).

Another antigen expressed on $>80 \%$ of NK cells is the T11/ $E$ rosette receptor (CD2). The T11 antigen, which is expressed on all $\mathrm{T}$ cells and thymocytes, has been shown to be a pathway for antigen-independent activation of peripheral blood $\mathrm{T}$ lymphocytes (5). Three different epitopes on the T11 antigen have been defined. The $\mathrm{T} 11_{1}$ epitope is closely associated with the sheep red blood cell receptor and is expressed on thymocytes, $T$ cells, and NK cells ( 3 ). The $\mathrm{T} 11_{2}$ epitope has the same tissue distribution as $T 11_{1}$ but is spacially distinct from the receptor for SRBC. The $\mathrm{T} 11_{3}$ epitope is absent on resting $\mathrm{T} 11^{+}$cells but is induced following $\mathrm{T}$ cell activation (5). By using a combination of both anti-T1 $1_{2}$ and anti-T1 $1_{3}$ monoclonal antibodies, it is possible to activate $\mathrm{T} 1^{+}$cells in vitro and induce expression of surface receptors for IL-2. Activation through the T11 structure is independent of expression of $T$ cell receptor for antigen and has been found to occur with immature thymocytes (6) as well as T3-negative NK clones (7). In addition, it has been demonstrated that cellular activation with anti-T11 monoclonal antibodies induces unrestricted killing by cytolytic $\mathrm{T}$ cell clones as well as cytotoxicity of NK clones against otherwise resistant targets (8). In the present studies, we demonstrate that the cytolytic function of peripheral blood NK cells can be markedly enhanced through activation of the CD2 and that this enhancement is comparable to that observed following IL-2 activation (9).

\section{Methods}

Monoclonal antibodies. The antibodies used in these studies have been previously described in detail. Anti-NKH $1_{A}$ is an IgM monoclonal antibody with identical specificity to anti-NKH1 (N901) (3). Anti-T1 $1_{2}$ and anti-T $11_{3}$ define two different epitopes of the $\mathrm{E}$ rosette receptor (5). $2 \mathrm{~F} 12$ is a monoclonal antibody recognizing the alpha chain of LFA-1 (10).

Cell lines. Molt4 is a T cell leukemic line. $\mathrm{K} 562$ is a cell line established from a patient with myelogenous leukemia. $\mathrm{OH}-1$ is a small lung cell carcinoma line provided by Dr. S. Bernal (11). SKRC is derived from a renal carcinoma and referred elsewhere as SKRC-1 (12). Mewo is a melanoma cell line (13).

Analysis and purification of subpopulations of human PBMC. PBMC were isolated from healthy volunteer donors by Ficoll-Hypaque density gradient centrifugation. Nonadherent cells were obtained from PBMC by $1 \mathrm{~h}$ adherence on plastic culture dishes at $37^{\circ} \mathrm{C}$. They were incubated with anti-NKH1 $1_{A}$ for $30 \mathrm{~min}$ at $4^{\circ} \mathrm{C}$, washed twice, and stained with fluorescein-conjugated goat anti-murine Ig for $30 \mathrm{~min}$ at $4^{\circ} \mathrm{C}$. After two 
additional washes, $\mathrm{NKH}^{+}$fluorescent cells were separated from nonfluorescent cells $\left(\mathrm{NKH}^{-}\right)$using flow cytometric cell sorting (FACS I, Becton-Dickinson \& Co., Mountain View, CA). Background fluorescence was determined with a nonreactive IgM antibody and positive cells were sorted in RPMI 1640 plus $1 \%$ pooled human AB serum at a rate of 3,000 cells/s. Reanalysis of purified populations confirmed that the positive fraction contained $>90 \%$ fluorescent cells and the negative fraction contained $<2 \%$ fluorescent cells.

Cytotoxicity assays. Cytotoxicity assays were performed according to a standard ${ }^{51} \mathrm{Cr}$ release method previously described (3). After cell sorter purification, fractionated cells were incubated with either recombinant interleukin-2 (rIL-2) medium (1,000 U/ml; Biogen S. A., Geneva, Switzerland) or anti-T $11_{2}$ and anti-T $11_{3}$ media $(1 / 250$ final dilution of ascites) in microtiter plates for $18 \mathrm{~h}$ at $37^{\circ} \mathrm{C}$ before adding ${ }^{51} \mathrm{Cr}$-labeled target cells. All reagents were subsequently left in the wells throughout the 4-h cytotoxicity assay. 18-h incubation with anti-T1 1 antibodies was found to be optimal for induction of cytotoxicity. Longer incubations with these reagents resulted in less enhancement. In contrast, rIL-2induced cytotoxicity was clearly evident at $18 \mathrm{~h}$ but in some instances was not maximal until after $48 \mathrm{~h}$ of incubation. All experiments were done in triplicate using $\mathrm{V}$ bottom microtiter plates. Medium was RPM1 1640 plus $5 \%$ pooled human $A B$ serum containing $50 \mathrm{U} / \mathrm{ml}$ penicillin and $50 \mu \mathrm{g} / \mathrm{ml}$ streptomycin. Assays were performed at various effector/ target $(E / T)$ ratios using between 3,000 and 5,000 targets cells per well. With all targets used, the minimum release (targets incubated in media alone) was $<\mathbf{2 0 \%}$ of the maximum release (targets incubated in $\mathbf{1 \%}$ Triton$X$ detergent). The results shown are the mean of triplicate experiments. Standard deviation is always $<5 \%$.

Conjugate formation assay. $\mathrm{NKH}^{+}$and $\mathrm{NKH}^{-}$sorted populations were incubated with either anti-T $11_{2}$ and anti-T $11_{3}$ monoclonal antibody media (1:250 final ascites dilution) or rIL-2 medium $(1,000 \mathrm{U} / \mathrm{ml})$ for $18 \mathrm{~h}$ at $37^{\circ} \mathrm{C}$. In control experiments, cells were incubated with anti$\mathrm{T}^{1} 1_{3}$ and anti-T1, another monoclonal antibody of the same isotype as anti- $\mathrm{T}_{1} 1_{2}$. Following incubation, cells were mixed with $\mathrm{K} 562$ targets at an E/T ratio of $20: 1$ in a final volume of $0.5 \mathrm{ml}$ and centrifuged for 5 min at $800 \mathrm{rpm}$. After various further incubation periods at $37^{\circ} \mathrm{C}$, the cells were gently resuspended with a pasteur pipette. Percent target cells forming conjugates with at least one effector cell was determined after enumeration of $200 \mathrm{~K} 562$ cells.

\section{Results}

Induction of cytotoxic activity in $\mathrm{NKHI}^{+}$cells. Human NK cells were purified from peripheral blood by immunofluorescent-flow cytometric cell sorting of $\mathrm{NKH1}^{+}$cells. When PBMC are separated into $\mathrm{NKH}^{+}$and $\mathrm{NKH}^{-}$fractions (Fig. $1 A$ ) all of the natural cytotoxicity against a standard NK target cell, $\mathrm{K} 562$, is contained within the $\mathrm{NKHI}^{+}$population. After 18 -h incubation with rIL-2 (Fig. $1 \mathrm{~B}$ ), the NK activity of unseparated PBMC is significantly enhanced and cytotoxicity remains confined to the $\mathrm{NKH}^{+}$subset. Results shown in Fig. $1 \mathrm{C}$ demonstrate that en-

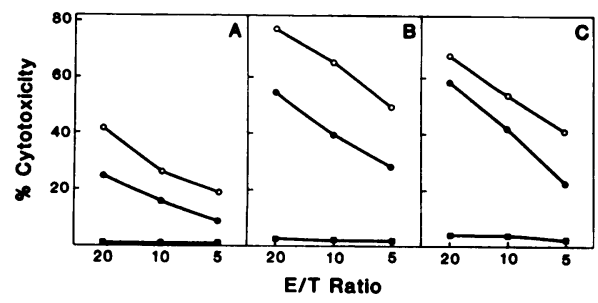

Figure 1. Activation of cytotoxicity against K562. NK activity of PBL (solid circle), $\mathrm{NKHI}^{+}$(open circle), and $\mathrm{NKH}^{-}$(solid box) cells was measured against K562 target cells after incubation with either media $(A)$, purified IL-2 $(B)$, or with anti-T1 $1_{2 / 3}$ monoclonal antibodies $(C)$. hancement of cytotoxicity can also be seen following 18-h incubation with anti-T $11_{2 / 3}$ monoclonal antibodies. Moreover, the triggering of peripheral blood NK cells with anti-T11 $1_{2 / 3}$ antibodies is as effective as with rIL-2 and is also restricted to $\mathrm{NKH1}^{+}$ cells.

Induction of conjugate formation following NK cell activation. To directly examine the effect of anti-T11 monoclonal antibodies on effector-target cell binding, we evaluated the ability of activated effector cells to form conjugates with K562 targets. As shown in Table $\mathrm{I}$, preincubation of $\mathrm{NKH}^{+}$cells with either anti-T $11_{2 / 3}$ or rIL-2 significantly enhances conjugate formation. This effect is stronger following anti-T $11_{2 / 3}$ than following rIL2 activation. Interestingly, conjugate formation is also induced in $\mathrm{NKH}^{-}$cells when activated through the $\mathrm{T} 11$ pathway although these cells are not able to mediate direct cytotoxicity. In contrast, rIL-2 does not induce the formation of conjugates in the $\mathrm{NKH}^{-}$population. In control experiments with the combination of monoclonal anti-T1 and anti-T $11_{3}$, there was no induction of cytotoxicity or conjugate formation with K562 targets (data not shown).

Effect of anti-LFA-1 antibody on induced cytotoxicity. The LFA-1 antigen has been shown previously to play an important role in the cell-cell interactions and formation of conjugates that occur during the cytolytic process of NK and other cytolytic cells (14). To characterize the role of LFA-1-mediated cell adhesion during T11-induced cytotoxicity, we added monoclonal 2F12 antibody to cells during activation before cytotoxicity assays. As shown in Fig. $2 B$, T11-mediated enhancement of cytotoxicity can be induced against additional NK target cells such as Molt4 resulting in more than a two-fold increase in cytotoxic activity after $18 \mathrm{~h}$ incubation at $37^{\circ} \mathrm{C}$. As seen previously with other target cells, cytotoxicity is contained within the $\mathrm{NKHI}^{+}$ fraction; very little killing can be found in the $\mathrm{NKH}^{-}$fraction either before or after T11 activation. When $2 \mathrm{~F} 12$ monoclonal antibody is added to the NK assay (Fig. $2 D$ ), cytotoxicity of T11-induced cells is reduced by $>50 \%$ and is similar to that observed before activation. These results suggest that the T11induced enhancement of cytotoxicity is at least in part due to an increased binding of effectors to target cells, mediated through LFA-1 antigen. Similar results were obtained with 2 F12 antibody and rIL-2-activated NK cells (data not shown).

Induction of cytotoxicity against resistant targets. To test whether T11 activation would induce cytotoxicity against NKresistant tumor cells, we performed similar experiments with

Table I. Effector-Target Cell Conjugates Induced by Anti-T11 $1_{2 / 3}$ and $r I L-2$

\begin{tabular}{|c|c|c|c|c|c|c|}
\hline \multirow[b]{2}{*}{ Time } & \multicolumn{3}{|c|}{$\mathrm{NKH} 1^{+}$cells } & \multicolumn{3}{|c|}{$\mathrm{NKH}^{-}{ }^{-}$cells } \\
\hline & Media & Anti-T $11_{2 / 3}$ & rIL-2 & Media & Anti-T $11_{2 / 3}$ & rIL-2 \\
\hline $20^{\prime}$ & $10^{*}$ & 50 & 44 & 4 & 88 & 0 \\
\hline $60^{\prime}$ & 10 & 68 & 52 & 8 & 94 & 8 \\
\hline $120^{\prime}$ & 32 & 72 & 46 & 6 & 96 & 2 \\
\hline
\end{tabular}

Peripheral blood mononuclear cells were separated into $\mathrm{NKH}^{+}$and $\mathrm{NKH} 1^{-}$populations by immunofluorescent cell sorting and subsequently incubated with either anti-T $11_{2}$ and anti-T $11_{3}$ or rIL-2. Following $18 \mathrm{~h}$ incubation, effector cells were incubated with K562 target cells for 20,60 or $120 \mathrm{~min}$ at $37^{\circ} \mathrm{C}$ before enumeration of conjugates. * Each value represents percent K562 target cells forming conjugates with at least one effector cell. 


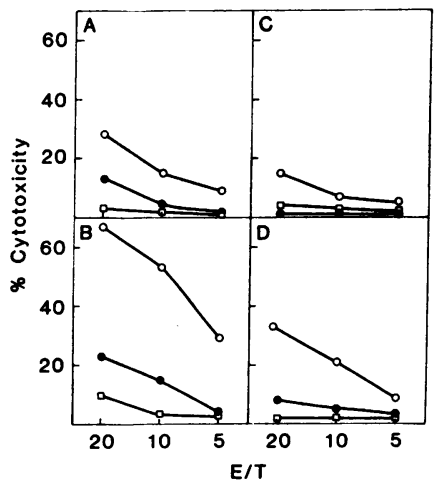

Figure 2. Effect of anti-LFA-1 antibody on cytotoxicity following T11 activation. Cytotoxic activity of PBL (solid circle), $\mathrm{NKH}^{+}$(open circle), and $\mathrm{NKH1}^{-}$(open box) effector cells against Molt4 target cells following incubation with me$\operatorname{dia}(A)$, anti-T1 $11_{2 / 3}$ monoclonal antibodies $(B)$, anti-LFA-1 monoclonal antibody at $1 / 250$ final dilution of ascites $(C)$, or anti-LFA- 1 and anti-T $11_{2 / 3}$ antibodies $(D)$.

three different solid tumor cell lines as targets. As shown in Fig. 3, the melanoma cell line Mewo and the renal cell carcinoma line SKRC are not killed by peripheral blood lymphocytes (PBL) incubated in media only. PBL are able to exhibit minimal killing (7\%) against the small-cell lung carcinoma line OH-1. After activation by anti-T $11_{2 / 3}$, PBL exert significantly more cytotoxicity against each of the three lines $(14 \%, 14 \%$, and $17 \%$, respectively). Comparing the cytotoxic activity of $\mathrm{NKH1}^{+}$and $\mathrm{NKH}^{-}$sorted cells after incubation in media only, we observed that $\mathrm{NKH}^{+}$ cells are able to mediate a low level of killing against $\mathrm{OH}-1$ cells ( $14 \%$ cytotoxicity) but very little cytotoxicity $(<6 \%)$ against Mewo and SKRC targets. $\mathrm{NKH}^{-}$cells are not able to kill any of these targets. After $\mathrm{T}_{1} 1_{2 / 3}$ activation, cytotoxicity of $\mathrm{NKH}^{+}$ cells is enhanced against all three targets, but $\mathrm{NKH1}^{-}$effectors have very little activity (always $<6 \%$ ). Similar induction of cytotoxicity within the $\mathrm{NKH}^{+}$population was observed following activation of effector cells with rIL-2. This data therefore supports the hypothesis that $\mathrm{NKH}^{+}$cells are responsible for both rIL-2 and T11-induced killing of NK-resistant targets by PBL.

\section{Discussion}

In summary, this study demonstrates that the cytotoxic function of purified $\mathrm{NKH}^{+}$peripheral blood NK cells can be significantly enhanced via the CD2 pathway. The extent of NK enhancement after an 18-h incubation period is quite similar to the effects seen after rIL-2 activation. Moreover, our data indicate that activation with either rIL-2 or anti-T1 $1_{2 / 3}$ monoclonal antibodies induces cytotoxicity against otherwise resistant target cells. The cell separation studies done in conjunction with in vitro acti-

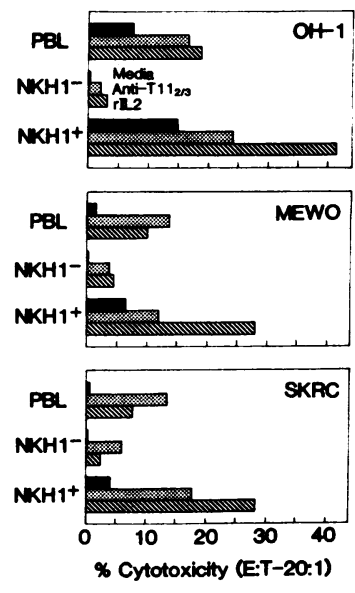

Figure 3. Induction of cytotoxicity against NK-resistant targets. Asșays were performed with PBL or purified $\mathrm{NKH}^{+}$and $\mathrm{NKH}^{-}$fractions after 18 $h$ incubation of the effectors with either media (solid bar), anti-T $11_{2 / 3}$ antibodies (stippled bar), and rIL-2 (hatched bar). OH-1 is a small-cell lung carcinoma line, Mewo is a melanoma line, and SKRC is the renal carcinoma cell line (SKRC-1). vation consistently demonstrate that cytotoxicity is contained almost exclusively within the $\mathrm{NKH}^{+}$cell fraction.

Although IL-2 and T11 activation lead to similar degrees of enhancement of cytotoxicity, there are differences in the effects of rIL-2 and anti-T $11_{2 / 3}$ that suggest that distinct cellular mechanisms may be involved. One major difference is the enhancement of conjugate formation in the $\mathrm{NKH1}^{-}$population that can be induced by anti-T $11_{2 / 3}$ but not rIL-2 (Table I). It is also known that $1 \mathrm{~h}$ incubation with IL-2 is sufficient for enhancement of cytotoxicity $(9,15)$ whereas the effects of anti-T11 antibodies require at least $6-8 \mathrm{~h}$ of stimulation before significant enhancement can be detected. Longer periods of incubation (48-72 h) result in decreased cytotoxicity (data not shown). The effects of these two activators on cloned NK and cytotoxic T lymphocyte effectors have also shown different results because only anti$\mathrm{T} 11_{2 / 3}$ is able to induce killing of resistant targets by cultured cell lines (8). In addition we have observed that rIL-2 induces proliferation as well as cytotoxicity of $\mathrm{NKH}^{+}$-purified cells whereas anti-T $11_{2 / 3}$ activation does not induce in vitro proliferation of these cells (data not shown and 16). Nevertheless it is known that $T 11_{2 / 3}$ activation results in rapid expression of IL2 receptor, and it is therefore possible that IL-2 may also play a significant role in the functional effects seen after stimulation with anti-T $11_{2 / 3}$. In this regard, the addition of both IL-2 and anti-T $11_{2 / 3}$ antibodies does not further enhance the activation of $\mathrm{NKH}^{+}$cells seen after either stimulus alone (data not shown). Further studies will be necessary to explore the different roles and potential mechanisms of interaction between IL-2 and T1 1 activation in the regulation of NK activity.

Another important issue addressed by the present studies is the identification of those cells capable of mediating cytotoxicity after in vitro activation. Other investigators have previously demonstrated that a subset of cells in normal peripheral blood can be induced to kill spontaneously a variety of target cells after in vitro incubation with rIL-2 (17). Clinical studies utilizing in vitro activated cytotoxic cells in patients with metastatic cancer have been reported recently (18). These cells have been termed lymphokine activated killer (LAK) cells, and some studies have suggested that they are distinct from both $\mathrm{T}$ cells and NK cells (19). The results presented in this report consistently demonstrate that spontaneous cytotoxicity against a variety of target cells is exclusively contained within the $\mathrm{NKH}^{+}$population of $\mathrm{PBL}$. In vitro activation by either rIL-2 or anti-T $11_{2 / 3}$ results in marked enhancement of cytotoxicity against $\mathrm{NK}$-sensitive targets as well as simultaneous induction of cytotoxicity against previously NKresistant targets. However with both stimulated and unstimulated effector cells, enhanced cytotoxicity remains confined to the $\mathrm{NKH}^{+}{ }^{+}$population that only represents a small fraction $(\sim 12 \%)$ of PBL. These studies therefore suggest that lymphokine-activated killing is a direct result of the activation of $\mathrm{NKH}^{+} \mathrm{NK}$ cells and argues against the presence of an additional population of cytolytic cells with a broad spectrum of reactivity. Similar findings have recently been reported by Lanier et al. (20). Taken together, these studies support the view that the LAK phenomenon primarily reflects the functional effects of various lymphokines in the regulation of NK activity in vivo.

\section{Acknowledgments}

We thank Dr. S. Bernal and Dr. C. Scott, who kindly provided the solid tumor cell lines, Gail Bartley and Hathy MacMahon for excellent technical assistance, and Ilene Isherwood for typing this manuscript. 
This work is supported in part by National Institutes of Health grant CA-41619. Dr. Schmidt is a recipient of a fellowship (Sch 596/1-1) from the Deutsche Forschungsgemeinschaft. Dr. Michon is a recipient of a research fellowship from the Institut National pour la Sante et al Recherche Medicale, France. Dr. Ritz is a scholar of the Leukemia Society of America.

\section{References}

1. Trinchieri, G., and B. Perussia. 1984. Human natural killer cells: biologic and pathologic aspects. Lab. Invest. 50:489-513.

2. Hercend, T., E. L. Reinherz, S. C. Meuer, S. F. Schlossman, and J. Ritz. 1983. Phenotypic and functional heterogeneity of human cloned natural killer cell lines. Nature (Lond.). 301:158-160.

3. Hercend, T., J. D. Griffin, A. Bensussan, R. E. Schmidt, M. A. Edson, A. Brennan, C. Murray, J. F. Daley, S. F. Schlossman, and J. Ritz. 1985. Generation of monoclonal antibodies to a human natural killer clone. Characterization of two natural killer-associated antigens, NKH1A and NKH2, expressed on subsets of large granular lymphocytes. J. Clin. Invest. 75:932-943.

4. Schmidt, R., C. Murray, J. F. Daley, S. F. Schlossman, and J. Ritz. 1986. A subset of natural killer cells in peripheral blood displays a mature T cell phenotype. J. Exp. Med. 164:351-356.

5. Meuer, S. C., R. E. Hussey, M. Fabbi, D. Fox, O. Acuro, K. A. Fitzgerald, J. C. Hodgdon, J. P. Protentis, S. F. Schlossman, and E. L. Reinherz. 1984. An alternative pathway of T cell activation: a functional role for the 50KD T11 sheep erythrocyte receptor protein. Cell. 36:897906.

6. Fox, D. A., R. E. Hussey, K. A. Fitzgerald, A. Bensussan, J. F. Daley, S. F. Schlossman, and E. L. Reinherz. 1984. Activation of human thymocytes via the 50KD T11 sheep erythrocyte binding protein induces the expression of interleukin 2 receptor on both T3+ and T3- populations. J. Immunol. 134:330-335.

7. Schmidt, R. E., T. Hercend, D. A. Fox, A. Bensussan, G. Bartley, J. F. Daley, S. F. Schlossman, E. L. Reinherz, and J. Ritz. 1985. The role of interleukin 2 and $\mathrm{T} 11 \mathrm{E}$ rosette antigen in activation and proliferation of human NK clones. J. Immunol. 135:672-678.

8. Siliciano, R. F., J. C. Pratt, R. E. Schmidt, J. Ritz, and E. L. Reinherz. 1985. Activation of cytolytic $T$ lymphocytes and natural killer cell function through the T11 sheep erythrocyte binding protein. Nature (Lond.). 317:428-430.

9. Henney, C. S., K. Kuribayashi, D. E. Kern and S. Gillis. 1981. Interleukin 2 augments natural killer cell activity. Nature (Lond.). 291: 335-338.
10. Schmidt, R. E., R. P. MacDermott, G. Bartley, M. Berkovitch, D. A. Amato, F. K. Austen, S. F. Schlossman, R. L. Stevens, and J. Ritz. 1985. Specific release of proteoglycans from human natural killer cells during target lysis. Nature (Lond.). 318:289-291.

11. Bernal, S. D., and J. A. Speak. 1984. Membrane antigen in small cell carcinoma of the lung defined by monoclonal antibody SM1. Cancer Res. 44:265-270.

12. Ueda, R., H. Shiku, M. Pfreundschuh, T. Takahashi, L. T. C. Li, W. F. Whitmore, H. F. Oettgen, and L. J. Old. 1979. Cell surface antigens of human renal cancer defined by autologous typing. J. Exp. Med. 150:564-579.

13. Carey, T. E., T. Takahashi, L. A. Resnick, H. F. Oettgen, and J. J. Old. 1976. Cell surface antigens of human malignant melanoma: mixed hemadsorption assays for humoral immunity to cultured autologous melanoma cells. Proc. Natl. Acad. Sci. USA. 73:3278-3282.

14. Krensky, L., F. Sanchez-Madrid, E. Robbins, J. A. Nagy, T. A. Springer, and S. J. Burakoff. 1983. The functional significance, distribution, and structure of LFA-1, LFA-2 and LFA-3. Cell surface antigens associated with CTL target interactions. J. Immunol. 131:611-616.

15. Itoh, K., A. B. Tilden, and C. M. Balch. 1986. Lysis of human solid tumor cells by lymphokine activated natural killer cells. J. Immunol. 136:3910-3915.

16. Ythier, A., L. Delmon, E. Reinherz, A. Nowill, P. Moingeon, Z. Mishal, C. Bohuon, and T. Hercend. 1985. Proliferative reponses of circulating human NK cells: delineation of a unique pathway involving both direct and helper signals. Eur. J. Immunol. 15:1209-1215.

17. Rosenberg, S. A., E. A. Grimm, M. McGrogan, M. Doyle, E. Kawasaki, K. Koths, and D. F. Mark. 1984. Biological activity of recombinant interleukin 2 produced in Escherichia Coli. Science (Wash. DC). 223:1412-1415.

18. Rosenberg, S. A., M. T. Lotze, L. M. Muul, S. Leitman, A. E. Chang, S. E. E. Hinghausen, Y. L. Matory, J. M. Skibber, E. Shilour, J. T. Vetto, C. A. Seipp, C. Simpson, and C. M. Reichert. 1985. Observations on the systemic administration of autologous lymphokine-activated killer cells and recombinant interleukin-2 to patients with metastatic cancer. N. Engl. J. Med. 313:1485-1492.

19. Grimm, E. A., K. M. Ramsey, A. Mazumder, D. J. Wilson, J. Y. Djeu, and S. A. Rosenberg. 1983. Lymphokine-activated killer cell phenomenon II. Precursor phenotype is serologically distinct from peripheral $\mathrm{T}$ lymphocytes, memory cytotoxic thymus-derived lymphocytes, and natural killer cells. J. Exp. Med. 157:884-897.

20. Phillips, J. H., and L. L. Lanier. 1986. Dissection of the lymphokine-activated killer phenomenon. Relative contribution of peripheral blood natural killer cells and T lymphocytes to cytolysis. J. Exp. Med. 164:814-825. 